\title{
Economics of climate policy and collective decision making
}

\section{Journal Article}

\section{Author(s):}

Bürgenmeier, Beat; Baranzini, Andrea; Ferrier, Catherine; Germond-Duret, Céline; Ingold, Karin; Perret, Sylvain; Rafaj, Peter; Kypreos, Socrates; Wokaun, Alexander

\section{Publication date:}

2006-11

\section{Permanent link:}

https://doi.org/10.3929/ethz-b-000002332

\section{Rights / license:}

In Copyright - Non-Commercial Use Permitted

\section{Originally published in:}

Climatic Change 79(1-2), https://doi.org/10.1007/s10584-006-9147-x 


\title{
Economics of climate policy and collective decision making
}

\author{
Beat Bürgenmeier • Andrea Baranzini · \\ Catherine Ferrier · Céline Germond-Duret • \\ Karin Ingold • Sylvain Perret • Peter Rafaj • \\ Socrates Kypreos • Alexander Wokaun
}

Received: 10 November 2004 / Accepted: 13 April 2006 / Published online: 8 November 2006

(C) Springer Science + Business Media B.V. 2006

\begin{abstract}
This paper explores the reasons why economic instruments of climate change are reluctantly applied and stresses the need for interdisciplinary research linking economic theory and empirical testing to deliberative political procedures. It is divided in three parts. The first one recalls the main issues in implementing Cost-Benefit Analysis such as information problems, uncertainties, discounting the future and irreversibilities. The second part shows how these issues can be treated in integrated assessment and techno-economic models and presents a case study, which shows that
\end{abstract}

- The chosen scenario tends to stabilize atmospheric $\mathrm{CO}_{2}$ concentration at around $550 \mathrm{ppm}$ in the long run.

- Exclusion of possibility to trade $\mathrm{CO}_{2}$ emission permits under a cap regime would increase the cost of emission abatement for OECD countries.

- Combining different flexibility instruments might lead to significant gains in the overall cost of climate policy.

The third part presents results of a survey conducted among the main economic and environmental associations in Switzerland. The survey reveals conflicting views on economic

B. Bürgenmeier $(\bowtie) \cdot C$. Ferrier $\cdot$ K. Ingold $\cdot$ S. Perret Centre of Human Ecology and Environmental Sciences, University of Geneva, 40 Bd du Pont-d'Arve, CH-1211, Geneva, Switzerland

e-mail: Beat.Burgenmeier@ses.unige.ch

\section{A. Baranzini}

Geneva School of Business Administration, University of Applied Sciences of Western Switzerland

C. Germond-Duret

Graduate Institute of International Relations, University of Geneva

S. Kypreos · A. Wokaun

Paul Scherrer Institute

P. Rafaj

International Institute for Applied Systems Analysis, Austria 
instruments. It shows how the social acceptability of these instruments can be improved in taking explicitly into account these opposing views of special interest groups. Therefore, policy scenarios should be selected in combining techno-economic models with empirical studies about their political and normative context.

\section{Introduction}

Climate change calls for a policy response. The Kyoto Protocol explicitly refers to economic instruments and delegates their application to the ratifying States. However as the OECD noted, these instruments are theoretically well founded, but badly applied (Barde 1997). This chapter examines the reasons for this limited success of economic instruments and explores some conceptual problems and in implementing Cost-Benefit Analysis in a political decision making process. Different policy recommendations face a social acceptance problem indeed (cf. Spash and Carter 2002).

This contribution is divided into three parts. The first one recalls some theoretical aspects of economic instruments based on cost-benefit analysis (CBA). The second one presents case studies for greenhouse gas emission control using models of the NCCR project to overcome the weaknesses related to CBA or the precautionary principle. Based on neoclassical economic theory and the use of techno-economic models some policy responses are evaluated. Finally, the third part, discusses the social acceptance problem in presenting the result of a survey conducted among 240 Swiss economic and the nine main environmental associations that form the main special interest groups in the implementation process of climate change policies. As a way of conclusion, some fundamental issues of economic instruments for climate change policy are discussed as controversies on their implementation are at the root of their social acceptance.

\section{Issues in implementing cost-benefit and cost effectiveness analysis}

The global warming problem can be addressed through five interrelated questions:

i By how much should greenhouse gases (GHGs) emissions be reduced? Answers to this question would help, for instance to assess the reduction targets actually discussed at the international level, e.g. in the Kyoto Protocol.

ii When should GHGs emissions be reduced? This issue is related to the timing of emissions abatement, e.g. is it better to reach a predetermined target relatively fast or is it preferred to wait and benefit from new information and technological advances?

iii How should emissions be reduced? This question is closely associated with the choice of policy instruments (e.g. regulations, economic instruments, voluntary agreements, and public investments) that could be implemented to achieve the required targets.

iv Who should reduce emissions? Responses to this interrogation involve equity considerations on, in particular, who has to bear the burden of the costs of climate policies and impacts.

v At which level should the decision intervene? Though climate change is a global phenomenon, actions are needed on all levels of intervention; the link between the international, national and local levels raises a coordination problem, as different jurisdictions intervene. 
The answers to these questions are particularly challenging, because of the peculiar features of the global warming problem, such as large uncertainties, non-linearities and irreversibilities, possible catastrophes with small probabilities, asymmetric distribution of impacts, very long planning horizon, changing social perception, and the global and public good characteristics of the problem (IPCC 1996).

CBA plays a prominent part in modelling economic decision-making procedures (cf. Nordhaus (1993), Falk and Mendelsohn (1993), and Maddison (1995)). CBA is a decision support technique, which was initially developed for project evaluation. The aim of CBA is to maximise economic efficiency or, in other words, to determine (economically) optimal policies. To achieve this, the CBA approach expresses widely different impacts in monetary terms, usually using market prices (or adjusted market prices, when markets are distorted or when the policy implies non-marginal changes). CBA applies a discounting procedure, to account for the fact that benefits and costs occur in different points in time.

To evaluate climate policies in a CBA framework, it is then necessary to calculate the ratio of the sum of expected discounted benefits $(V)$ and costs $(F)$ of reducing global warming, $Y_{0}=V_{0} / F_{0}$. Where

$$
V_{0}=\sum_{t=0}^{T} \frac{B_{t}}{(1+r)^{t}} \quad \text { and } \quad F_{0}=\sum_{t=0}^{T} \frac{C_{t}}{(1+r)^{t}}
$$

with $B_{t}$ and $C_{t}$ the expected benefits and costs at time $t, r$ the appropriate discount rate, and $T$ the time horizon.

The discounted costs are the monetary costs of abatement policies, while discounted benefits are the level of damage avoidance-the difference between the cost of global warming in the absence of intervention and the unavoidable costs of global warming associated with a given abatement policy (which cannot be avoided because greenhouse gases are long-lived).

Following the CBA approach, a policy improves economic efficiency if discounted benefits are greater than discounted costs (i.e., when $Y_{t}=V_{t} / F_{t}>1$ ). When there are alternative climate policies, the optimal is the one with the greatest difference among the sum of discounted benefits and cost.

\subsection{Information problems}

To implement the CBA approach, it is thus necessary to know and quantify all the previous parameters, i.e. costs, benefits and the discount rate, as well as their evolution through time. Of course, in the context of global warming, this is an incredibly complex task and it has to overcome an extraordinary information problem. Moreover, if global warming in the very long term will banish life on Earth, then only the costs to avoid this outcome have to be accounted for Benefits derived from human activities will disappear too.

The evaluation of costs of climate policies is illustrated in the GMM model, which will be presented in the second part of this chapter. The evaluation of the benefits of climate policies, especially in monetary terms, is much more subject to debate and dispute. Indeed, fundamental impacts of climate change are not subject to trading in markets, or are traded in very imperfect and limited markets. For instance, climate change may have impacts on human health and increase mortality and morbidity; may oblige people to migrate from an exposed area; or may modify ecosystems and reduce biodiversity. The most serious consequences of those impacts are of course outside the realm of the markets. In the past decade, a large body of the environmental economics literature developed and applied several techniques 
to value non-market assets in monetary terms, ranging from human capital techniques and defensive expenditures approaches to hedonic techniques and contingent valuation methods (e.g. see Cropper 2000). Those techniques are different in their application, but they are all fundamentally based on the same principle: simulate the existence of a market, for an asset, which is not marketed. Those techniques are thus inferring the willingness to pay (willingness to accept a compensation) of individuals for an improvement in environmental quality (decrease in environmental impacts). This implies that the monetary assessments of climate change are strongly conditioned by income and income distribution, which means that the value of similar impacts, such as the risks to human life, turns out to be very different in different countries (see Anaheim 2002).

However, economic valuation techniques are but one step in the complex process for the monetary valuation of the benefits of climate change policies. As E. J. Mishan pointed out: “... benefits aggregates, of course, no longer carry any independent economic recommendation. They are value only insofar as they are made use of by the political authority as an input into the decision making process, an input to which any weight/including a zero weight) can be attached" (Mishan 1980, p. 157). Therefore, valuation of the benefits of climate change policies is an interdisciplinary endeavour, involving sciences like climatology, epidemiology and ecology, while economic techniques are then used to express the impacts in monetary terms, and other social sciences can be implicated to assess their social pertinence. But expressing costs and benefits of climate change policies in monetary terms is challenged by the view that the main aspects of environment evaluation fundamentally escape quantification and involves beliefs and finally symbolic social representations of nature, which cannot be expressed in monetary terms (cf. Funtowicz and Rawetz 1994).

\subsection{Uncertainties}

Monetary valuation will inevitably be faced with fundamental uncertainties. Those uncertainties will never be solved, since valuation has to be carried out not only for the present, but also for the future. Indeed, in the future we will not only have different economies, but different individuals and societies, with different preferences and attitudes. According to Arrow et al. (1996), those uncertainties may be classified in three areas:

- Scientific uncertainties, which relate e.g. to the relationships between ghg emissions and concentrations, climate feedbacks, and effects of climate change on temperature and on biogeo-chemical cycles. The understanding of global climate change and its inter-connexions with microclimate change is only at its beginnings. This link may be of crucial importance for implementing climate change on national or regional levels.

- Socio-ecologic uncertainties, concerning the relationships between human societies and nature, e.g. agriculture production and diseases, water use and air pollution.

- Socio-economic uncertainties, which are connected to the effects of climate change on human welfare.

\subsection{Discounting the future}

The final parameter that has to be quantified to apply the CBA approach is the discount rate. The issue of the correct discount rate to be used in CBA is an endless debate in economics, which can be traced back to Ramsey (1928). Ramsey contended that at the public level it is not ethically defendable to actualise future generations' welfare (i.e. the discount rate should be nil). In the climate change context, the role of the discount rate is amplified, given the 
very long planning horizon. Indeed, using a real discount rate of 5 to 10 percent (as used in many public projects) corresponds to artificially shortening the time horizon. In other words, a relatively high discount rate implies that some of the impacts of climate policies will not be considered, when they will occur relatively far into the future (e.g. 50 to 100 years from now). For instance, 1 million damages in 100 years resulting from climate change is worth in present value about 70 if discounted at $10 \%$, about $7^{\prime} 600$ discounted at $5 \%$ and 370 '000 at $1 \%$.

The choice of the discount rate will thus have a decisive impact on the optimality of a given climate policy. In fact, given the very long time horizon, climate change strengthens the tradeoff concerning the ambivalent role of the discount rate as a mean to reach simultaneously the efficiency in the inter-temporal allocation of resources and inter-generation equity. How can efficiency be separated analytically from equity in order to recommend economic policies to climate change though in the implementation process both are interrelated? The discount rate, which also refers to the inter-temporal efficiency and equity, can only be analysed with reference to the social objective function (cf. Burgenmeier 2003). For the latter, it means that it is necessary to consider the ethical foundations of maximising the sum of discounted net benefits as the social objective (of climate change policies). Indeed, maximising the sum of discounted net benefits (which corresponds to the CBA Social objective) does not prevent decreasing net benefits for some generations, which may be in contrast with the concept of sustainable development where the common denominator is an ethical claim of intergenerational equity.

For the inter-temporal efficiency aspects, the discount rate should reflect the opportunity costs of future social net benefits (benefits minus costs) resulting from a given policy. At the individual level, the discount rate is likely to be greater than zero, if capital is productive and if individuals have a preference for the present vs. the future. It can be shown that the individual discount rate of consumption $\left(r_{c}\right)$ is equal to (cf. Hanley 1992): $r_{c}=\rho+\varepsilon(c) \frac{\dot{c}}{c}$, with $\rho$ the individual "pure" time preference (due to impatience, the limited duration of life and uncertainty) and $\varepsilon(c)$ the elasticity of the utility of consumption. Thus, even if the pure time preference is nil, the individual discount rate can be positive, if consumption is growing.

If capital markets are perfectly competitive, the interest rate is a good measure of the individual discount rate. However, in reality capital markets are often distorted. In addition, and more fundamentally, the individual discount rate may be different from the one that society would use to express preferences through time. There are several reasons, which may justify that the social discount rate is lower than the individual one. In particular, contrary to individuals, society has a planning horizon that is infinite, since its expected life is (hopefully) not finite. Moreover, some risks may be spread at the collective level, whereas it is not possible at the individual level. In their seminal paper Arrow and Lind (1970) have even demonstrated that if the risk may be perfectly spread, then the community may be considered as risk neutral, even if it composed of risk-averse individuals. In that case, the discount rate should not be corrected (increased) to account for uncertainty.

However, the risks associated with climate change are relatively difficult to spread, in particular those related to catastrophic events. Indeed, those risks may be very high and thus different from zero, even when divided among a (finite) number of individuals. In addition, these kinds of risks possess public good characteristics and thus it cannot be divided between individuals, since uncertainty will nevertheless remain the same for each individual (non-rivalry).

\subsection{Uncertainty, irreversibilities and climate catastrophes}

As detailed above, uncertainty is an inherent feature of climate change. Moreover, the effects of uncertainty on optimal abatement policies are amplified by irreversibility. In the literature, 
irreversibility possesses two forms (see Goldemberg et al. 1996). A decision may be considered as irreversible when it reduces future possibilities of choice for a long period of time (Henry 1974).

The first is the irreversibility of climate change: once GHG emissions go into the atmosphere, they can only be removed naturally, but the rate of decay is extremely low, in particular for $\mathrm{CO}_{2}$. The second is capital irreversibility: to control ghg emissions, significant investments could be involved, and once made, they cannot be undone quickly.

The possibility of catastrophic events is also a main feature of global warming. Indeed, climate change could be a gradual and slow process, but some of its impacts may occur abruptly or over a short period of time, as some climatological parameters cross threshold values (National Research Council 2002). Examples of sudden global warming catastrophes are:

(i) The "runaway" greenhouse effect (climate change is much greater and occurs much faster than the common consensus indicates);

(ii) Disintegration of the West Antarctic Ice Sheet;

(iii) Structural changes in ocean currents (which may lead to a sharp drop in European mean temperatures).

The first studies applying CBA to determine optimal climate policies did not address these important features, but there is now a substantial literature, which extends traditional CBA to account for uncertainty and irreversibility in the global warming context. However, only a few authors have attempted to include the possibility of catastrophic events (c.g. Baranzini et al. (2003), who show that (i) gradual, continuous uncertainty in the global warming process is likely to delay the adoption of optimal abatement policies, with respect to the standard CBA; but (ii) the possibility of climate catastrophes accelerates the implementation of these policies as their net discounted benefits increase significantly).

\section{CBA in integrated assessment and techno-economic models}

Having in mind the fundamental critique of CBA for setting climate-change policies described before, we operate two models of the NCCR project to address these questions.

First the Integrated Assessment Model (IAM) MERGE is applied in a CBA framework or under the precautionary principle to describe scenarios that stabilise the carbon concentration or the maximum temperature change to low levels. MERGE is able to address issues of uncertainties for key parameters like the climate sensitivity and the ocean diffusivity in a stochastic framework where uncertainties will be resolved in the future (Manne and Richels 2005).

This IA model can be also extended to address problems of non-linearity and irreversibility or climate catastrophes. For example, the MERGE-E version (Bahn et al. 2006b) specifies time constraints on temperature changes and rates of temperature changes such that the thermohaline circulation (THC) of the North Atlantic will never be interrupted. Temperature constraints are estimated with the help of specific climate models (Knutti et al. 2002) concerning the THC. Examples applying MERGE are given in the same special issue (Bahn et al. 2006a). The report of Bahn et al. describes how a neoclassical economic model like MERGE can be linked with a climate model of intermediate complexity to perform analyses in a CBA or in a cost effectiveness framework.

The second model applied in the NCCR project is the energy systems model GMM (a partial equilibrium bottom-up model) where following the precautionary principle we evaluate different policies and targets that stabilize carbon emissions to $10 \mathrm{GtC} / \mathrm{yr}$ by the year 2050. These case studies are imposed as a set of policy overlays on a Baseline sce- 
nario to define the responses to climate change. The case studies are described in some details here and explain how the "what", "where", "when" and the "technological" flexibility can be realized. The model is also used to perform sensitivity analyses on the discount rate.

The GMM model is a technology oriented "bottom-up" model that obtains the least-cost configuration of the global energy system for a given time horizon (50 years) under a set of climate-response policy settings (Rafaj et al. 2005). At the same time, GMM endogenises the technological learning (ETL) for emerging technologies, as is described in detail in Viguier et al. (2006) also in this volume. The economic feedback of climate-response policies is captured in GMM by the partial equilibrium procedure, in which the model calculates its objective function as a sum of (a) the energy/technology production cost and (b) the loss of consumer welfare associated with demand reduction.

In the case of climate policies, the change in the objective function, i.e., an increase or decrease in the total cumulative discounted system cost over the reference development indicates the cost impacts of a specific policy instrument applied (Loulou et al. 2004).

Another economic indicator that is frequently used for the evaluation of climate policies is the marginal abatement cost, which defines the cost of reduction of the last unit of GHG emission in order to reach the prescribed emission level. Both indicators, i.e., the change in the total system cost, as well as marginal abatement cost of GHG reduction are used below for the evaluation of different setups of climate policies.

The way, in which questions of cost effectiveness or CBA with respect to climate polices can be translated into the formalised GMM modelling framework, is exemplified using an illustrative policy scenario GHG-Cap\&Trade and its modalities that reflect different climate policy setups and flexibility mechanisms as being imposed on the Baseline development.

Section 3.1 refers to cost effectiveness analyses with GMM while Section 3.2 to CBA.

\subsection{Illustrative policy scenarios}

The selection of the reference case is crucial for the modelling-based policy analysis, therefore a short description of the Baseline scenario and its assumption is provided here. The Baseline scenario that underlines all policy cases is closely related to the B2 scenario reported by the IPCC (2000). The baseline storyline assumes a given degree of increased concern for environmental and social aspects and is consistent with current institutional frameworks and current technology dynamics. Although not calibrated to match exactly the results of the original B2 scenario, the Baseline scenario reported herein may represent a plausible development of the global energy system. The allocation of resources is based on an optimisation performed under conditions of perfect foresight with ETL considerations included. In addition, global spillovers of experience and knowledge transfer (including from North to South) are assumed to take place. Time evolution of global energy related $\mathrm{CO}_{2}$ and other GHG emissions in the reference development are summarised in Figure 1. Total global energy-related carbon emission rates in the Baseline scenario increase continuously from the present level of $6.3 \mathrm{GtC} / \mathrm{yr}$ throughout the time horizon modelled, giving an annual rate of $1.97 \% / \mathrm{yr}$ and reaching a level of $16.8 \mathrm{GtC} / \mathrm{yr}$ by the year 2050. Inclusion of non- $\mathrm{CO}_{2}$ gases in the Baseline increases the total carbon-equivalent (C-eq) emissions to $19 \mathrm{GtC}-\mathrm{eq} / \mathrm{yr}$ in the year 2050.

\subsection{1 "How much and what?"}

The total level of $\mathrm{CO}_{2}$ reduction in the GHG-Cap\&Trade scenario follows in our example a precautionary principle that imposes a stabilising cap on the global energy-related $\mathrm{CO}_{2}$ 


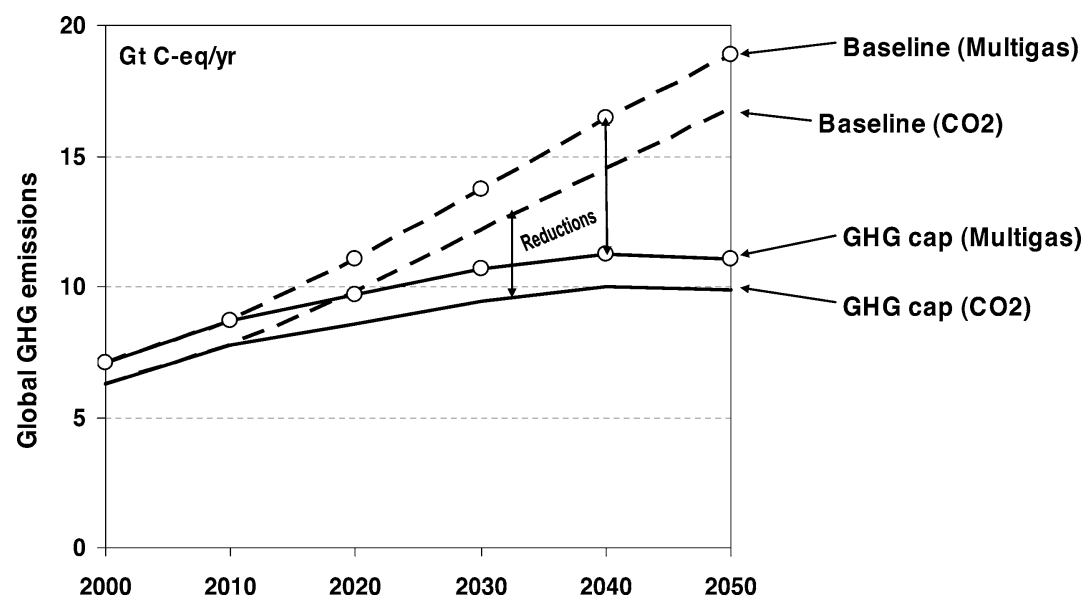

Fig. 1 Global GHG emissions $\left(\mathrm{CO}_{2}, \mathrm{CH}_{4}, \mathrm{~N}_{2} \mathrm{O}\right)$ in the Baseline scenario and the reduction target in the $\mathrm{CO}_{2}$ and Multigas-mitigation scenarios

emissions to $10 \mathrm{GtC} / \mathrm{yr}$ by the year 2050 . The global emission trajectory considered in this exercise might in a long run lead to a stabilisation of the atmospheric $\mathrm{CO}_{2}$ concentration at around $550 \mathrm{ppm}$. Inclusion of non- $\mathrm{CO}_{2}$ GHGs (i.e., the multigas abatement strategy) increases the reduction target in 2050 to $11 \mathrm{GtC}$-eq/yr proportionally to the higher level of GHG emissions in the Baseline, as is illustrated in Figure 1.

Consideration of non- $\mathrm{CO}_{2}$ GHGs involves the first type of flexibility in the climate policymaking and refers to the "what" flexibility, i.e., the possibility to abate the most cost-efficient mix of GHGs in a given time period. The Kyoto protocol identifies six substances that can contribute to reaching the overall GHG mitigation goal (UNFCCC 1999). In addition to $\mathrm{CO}_{2}$, the GMM considers emissions of methane $\left(\mathrm{CH}_{4}\right)$ and nitrous oxide $\left(\mathrm{N}_{2} \mathrm{O}\right)$. Although the $\mathrm{CO}_{2}$ emissions associated with the fossil-fuel combustion represent the far largest contribution to the total GHG-emission levels, ignoring other Kyoto-gases would lead to the abandonment of a range of cost-efficient abatement options and potential gains because of substitution among gases. The impact of "what" flexibility on the overall cost of GHG mitigation policy is depicted in Figure 2, showing the cost-reducing effect of multigas abatement strategies.

\subsection{2 "Who and where?"}

The allocation of emission entitlements across world regions in the GHG-Cap\&Trade scenario is based on an assumption of extending the Kyoto protocol targets beyond the first commitment period of 2008-2012 to the global level such that a smooth global $\mathrm{CO}_{2}$ emission trajectory to $10 \mathrm{GtC} / \mathrm{yr}$ will be obtained while taking into consideration the aspiration of developing countries for economic growth. The allocation principles for the distribution of entitlements are described in Rafaj et al. (2005). The Kyoto protocol suggests a number of international mechanisms, with which the reduction commitments can be achieved more efficiently at a minimum cost. These mechanisms take advantage of the "where" flexibility of mitigation. The case study presented herein introduces the "where" flexibility through a generic GHG-emission trading scheme without distinguishing between the specifics of Kyoto-instruments, i.e., IET, JI, or CDM. As is shown in Figure 3, exclusion of possiSpringer 

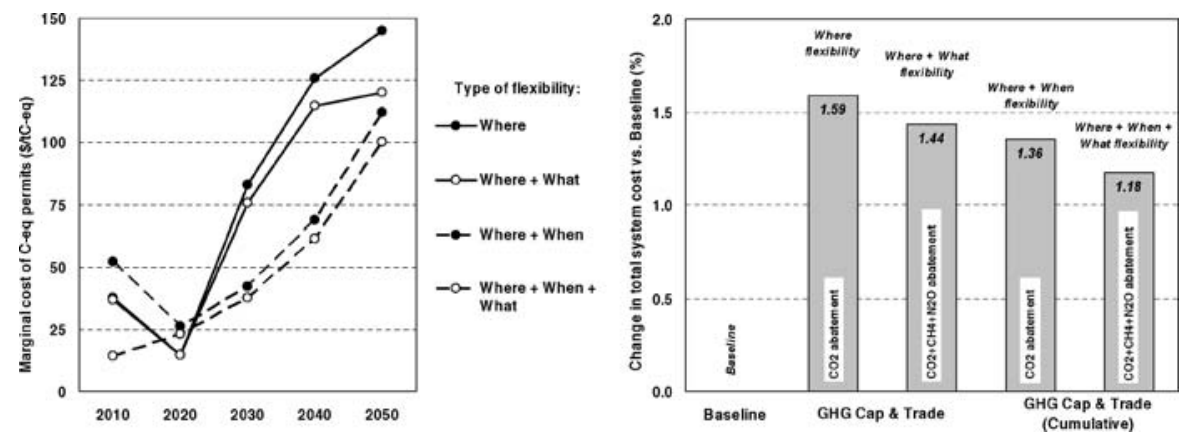

Fig. 2 Cost impacts of the flexibility mechanisms for the GHG-abatement strategies. Under the "when" flexibility case a cumulative emission constraint for the period 2010-2050 is imposed instead of annual emission targets
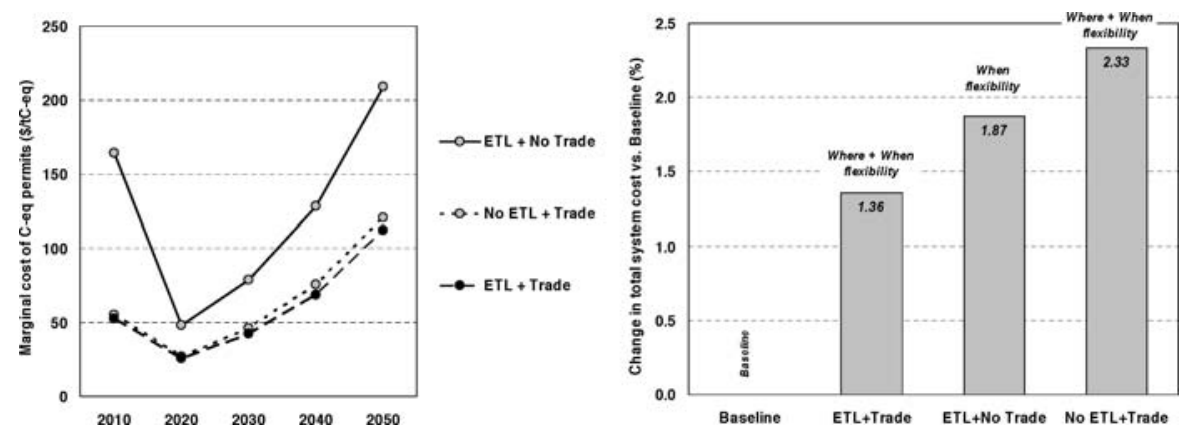

Fig. 3 Cost impacts of the "technological" flexibility and international trading with C-eq emission permits

bility to trade $\mathrm{CO}_{2}$ emission permits under a carbon cap regime would increase the cost of emission abatement for regions with expensive mitigation possibilities, such as OECD region.

\subsection{3 "When?"}

The timing of imposition of stringent climate policies is particularly important for the policy acceptability. Considering the climate change as a global problem with long-term consequences, the question is how to allocate the global carbon budget over time to achieve cost optimality in achieving a given policy goal. In GMM, this question is addressed by using a "cumulative" GHG constraint for the whole commitment period, i.e., 2010-2050. This constraint is equal the integral of the regionalised annual targets introduced above, and involves the "when" flexibility in GHG mitigation. Optimal timing in GHG reductions is associated with important cost impacts. Marginal cost reduction due to "when" flexibility is quantified in 2050 at about $35 \$ / \mathrm{tC}$-eq as compared to the GHG-Cap\&Trade case with annualised emission bounds. As shown in Figure 2, combining the different flexibility instruments, i.e., "where", "when" and/or "what", might lead to significant gains in the overall cost of climate policy. 


\subsection{4 "How and at which level?"}

Successful achievement of prescribed GHG-reduction targets requires the implementation of appropriate policy instruments. The Kyoto protocol and subsequent international agreements are less specific in the choice of methods to be used for domestic reduction efforts. Nevertheless, adoption of proper domestic policy instruments will be essential if the GHGreduction targets are to be met. Such policies could vary from application of "command \& control" regulatory options to a carbon tax or voluntary measures. Due to the level of regional aggregation, specific domestic policy instruments are not modelled individually in this case study, but they are assumed to be implicit to the emission cap imposed on the regional energy systems. A detailed analysis of the acceptance of a group of selected domestic policy instruments for Switzerland is provided in Section 4.

The question of "how" the emission reduction shall be realised is closely related also to the last type of flexibility addressed in this paper. The so called "technological" flexibility would refer to the ability of the energy system to adopt for a "carbon-constrained" world. Decarbonisation of the global energy system implies the substantial structural changes in the energy sector and deployment of advanced technology options. In this context it is interesting to evaluate the impacts of technological progress under the climate-policy regime. An example of this phenomenon is provided in Figure 3, where the costs of the GHG-Cap\&Trade policyscenario with ETL are compared with scenario that does not consider cost-reducing effects of technological learning.

\subsection{Information problems}

As discussed in Section 2.1., economic valuation of costs and benefits that could be linked to the adoption of climate policies is a complex task surrounded with a broad range of uncertainties. An example of valuation of potential benefits of the illustrative policy scenario GHG-Cap\&Trade is provided here based on avoided damages due to air pollution.

It is well recognised that climate policies could indirectly lead to a significant reduction in air polluting substances. This effect is considered as a secondary benefit of a climate policy. Reduction in air pollution might be substantial especially in the developing regions with relatively low air quality standards. The question that arises in the CBA context is how to monetize the avoided damage that would occur because of the implementation of climate policies with GMM.

An approach used in this exercise is to scale first the damages per unit of $\mathrm{kWh}$ of a specific power plant based on the results of the ExternE project (EC 1999). The information problem to be overcome is the adjustment of ExternE values of damage costs valid for typical conditions in Western Europe (based on specific willingness-to-pay (WTP) measures) to the regions with unknown WTP. The scaling method can be based simply on the population density of the affected region, or the welfare of affected population using expected projections of GDP. Then, based on the electricity generated by region and power stations in a scenario, one could estimate the avoided damages due to the climate policy adopted. As is illustrated in Figure 4 , the selection of a specific scaling approach leads to a significant difference in the value of avoided damage. The lower range of avoided damages in the figure represents the damage cost adjusted to the population density, and the upper range reflects the damage cost scaled to GDP in market exchange rates. The middle value reflects the scaling to the per capita GDP in purchase power parity (Rafaj 2005). Notice that in the same reference, the GMM model is Springer 


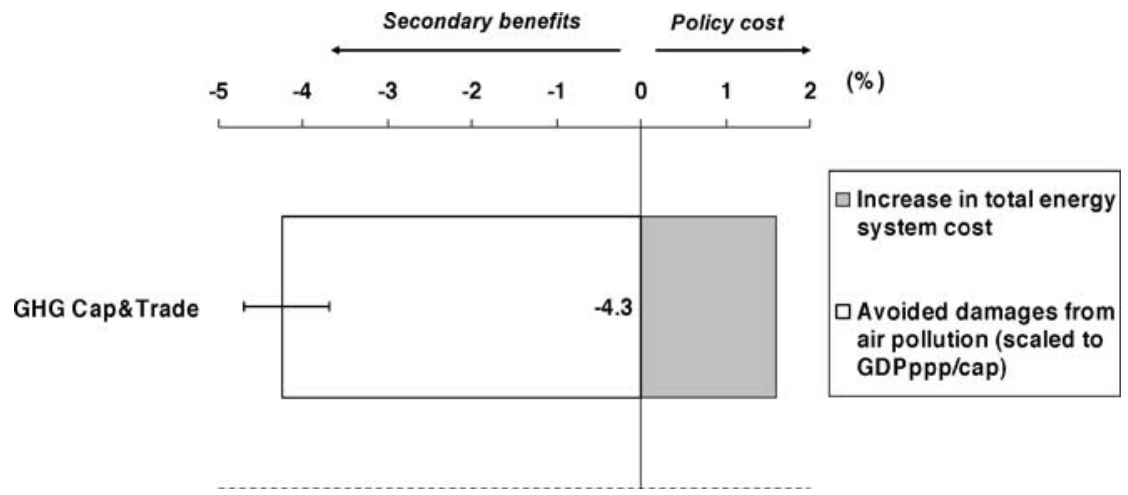

Fig. 4 Comparison of cost and secondary benefits for the GHG-Cap\&Trade policy scenario expressed as a change in the cumulative discounted energy system cost relative to the Baseline scenario. (Note: $\mathrm{d} r=5 \%$ )

used in a more formal CBA framework addressing simultaneously climate policies and the external costs associated with electricity generation.

Implications of the modelling results presented in Figure 4 can be highly relevant for policy-making efforts in the area of climate change, particularly for the developing countries, since they suggest that the secondary benefits of the $\mathrm{CO}_{2}$-abatement might offset the direct costs of mitigation.

\subsection{Discounting issue in the GMM modelling framework}

Given the controversy in the proper selection of the discount rate (dr) for climate policies outlined in Section 2.3., it is advisable to evaluate the cost impacts using different dr values. A 5\% per annum discount rate has been used in the Baseline and policy scenarios reported above. Two sensitivity cases are analysed herein for the GHG-Cap\&Trade scenario, using the values of $3 \%$ and $7 \%$. The rate of $3 \%$ is indicated by IPCC (2001) as a rate based on "ethical" considerations. The latter value of $7 \%$ reflects more the present energy-market situation and the $\mathrm{dr}$ value is used to approximate the cost of capital invested in more risky projects (see, e.g., AEN-NEA 2005).

Figure 5 shows the change in objective function over the Baseline for the GHG-Cap\&Trade scenario applying different discount rates of 3,5, and 7\%. For consistency, the cumulative system cost in the policy scenarios is compared to the Baseline scenario, calculated by using the same discount rates as in the policy cases. Variations in the total discounted cumulative cost relative to the Baseline disclose a decreasing trend in the total cost for the sensitivity scenarios with an increasing dr. The 3\%-discounting results in a total cost that is higher than in the scenarios with dr of 5 and $7 \%$. On the other hand, marginal costs (undiscounted) of C-eq permits globally traded across world regions are the highest in the case of $d r=7 \%$, which reflects the increase in the cost of investments in the abatement options needed for reaching the GHG-reduction target. This trend is pronounced in the second half of the computational period, where the carbon constraint is the most stringent.

\subsection{Final thoughts on the policy recommendations based on a modelling exercise}

The purpose of the modelling exercise presented in this section was to provide an example of how to handle the critical issues raised by CBA as pointed out in Section 2. Clearly, the 

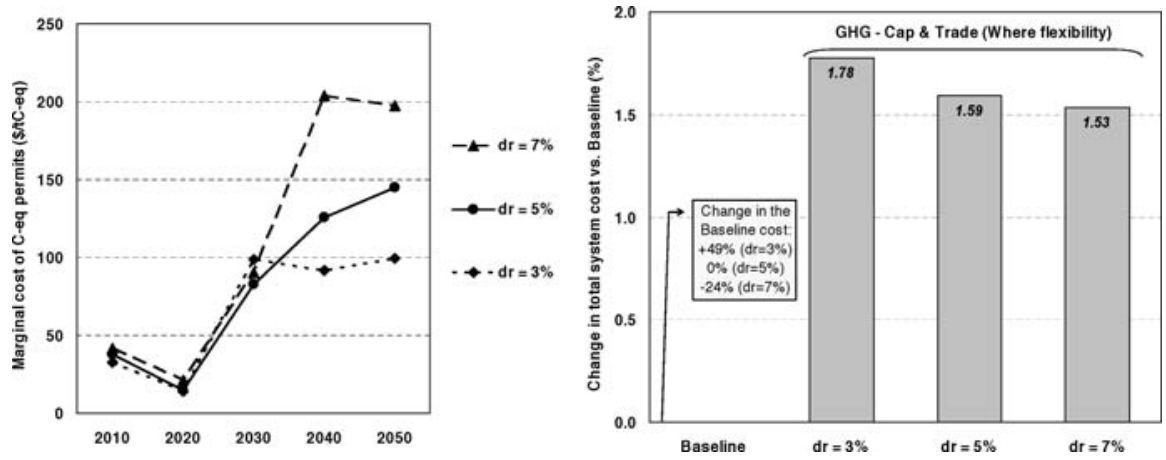

Fig. 5 Changes in the climate policy cost in relation to different discount rates

case study performed with the "bottom-up" GMM model suggests that a number of the key questions related to the climate policy-making can be addressed and the quantitative results provided might be used to support policy decisions.

The modelling results indicate that at the regional and global level the flexibility mechanisms for climate policies constitute powerful instruments to moderate the cost penalty invoked by the policy adoption. The analysis also shows that the combination of elements within a cost-efficient portfolio of climate policy instruments might provide significant gains and could potentially improve the acceptability of the policy implementation. At the same time, the successful implementation of climate policy tools is unthinkable without policy actions in favour of technology progress.

Overcoming the information problems associated with uncertainties (in, e.g., valuation of damages, the choice of discount rates, or irreversibility) represents a challenging task for any formalised modelling analysis. The results reported here illustrate that the choice of these key parameters influence the overall outcomes of a given policy-scenario. In this context it is highly relevant to explore, how the policy responses evaluated and proposed on the basis of neoclassical economic theory and the use of techno-economic models could be accepted by all relevant actors needed to reach a consensus in the debate on climate change policy specification.

\section{Social acceptance of policy recommendations}

When it comes to translate policy recommendations derived from modelling into the implementation process, considerable resistance can be observed. One of the main obstacles is linked to the distributional aspects of such policy recommendations. In order to overcome this obstacle, income redistribution proposes the recycling of tax revenues. However, using regional and individual data, Thalmann showed that for most voters the mode of revenue recycling did not matter during the Swiss vote on energy taxes in September 2000 (Thalmann 2001). Therefore, a more detailed study is needed in order to understand why there is such a resistance to climate change policy. Wallart identified the main factors for environmental tax opposition (Wallart 2000) and our own findings on the dilemma between theory and practice of economic instruments for environmental protection are based on an inquiry which we have conducted among the 300 most important Swiss corporations (Bürgenmeier et al. 1997).

The firms have been asked about the importance of the major objections raised in the public debate about the introduction of ecological taxes. Though the majority of the answers are 
overwhelmingly positive (66.7\%), a first proposal to implement a $\mathrm{CO}_{2}$ tax at the beginning of the ' 90 s has been rejected in the preliminary consulting process which precedes any new legislation in Switzerland. The majority of firms agree on an environmental tax, but reply through their professional organisations negatively in the consultation. It may be that these organisations have to protect the weakest member and reflect, therefore, the firms, which replied negatively. These responses may also illustrate the paradox of collective action, where in the decision-making process the collective outcome is in opposition to individual beliefs (Olson 1971).

Finally, another explanation is linked to the conditions in which ecological taxes are introduced. If these taxes are accepted as a principle only, they raise many objections as far as concrete and very much differentiated individual situations are concerned.

\subsection{Special interest groups and policy implementation}

In order to further explore the issue of social acceptability of economic instruments in the field of climate change, we have carried out another survey among 240 economic and 9 ecological associations in Switzerland during 2003. This research is part of a larger project, which deals more generally with the socio-economic aspects of climate research within the Swiss National Centre of Competence and Research on climate (Bürgenmeier et al. 2006).

Figure 6 shows that the Swiss economic associations are more favourable to the introduction of voluntary agreements and incentive measures, such as taxes and tradable emissions certificates, comparing with direct controls (i.e. regulation or standards). For each of the

\section{CI = Confidence Interval (95\%)}

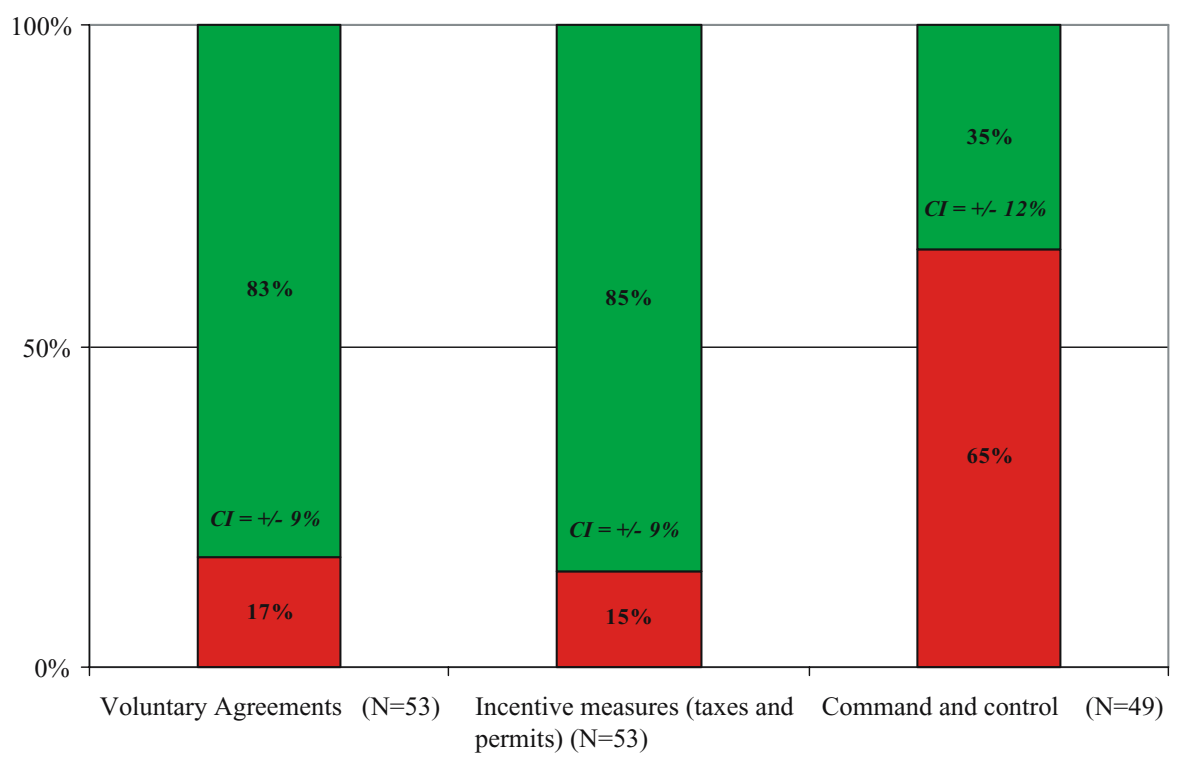

$\square$ unfavorable or rather unfavorable $\square$ favourable or rather favourable

Fig. 6 Introduction of climate policy instruments: Opinions of the Swiss economic associations 


\begin{tabular}{|c|c|c|c|c|c|c|}
\hline & $\begin{array}{c}\text { Voluntary } \\
\text { Agreements }\end{array}$ & $\begin{array}{c}\text { Information } \\
\text { Education }\end{array}$ & $\begin{array}{c}\text { Certificates } \\
\text { international }\end{array}$ & $\begin{array}{c}\text { Certificates } \\
\text { national }\end{array}$ & Taxes & $\begin{array}{c}\text { Command } \\
\text { and control }\end{array}$ \\
\hline $\begin{array}{c}\text { Economic } \\
\text { Associations }\end{array}$ & 1 & 2 & 3 & 4 & 5 & 6 \\
\hline
\end{tabular}

Fig. 7 Ranking of preferences of forty-nine Swiss economic associations for economic instruments

three measure, we directly asked the associations if they were favorable (or not) to their introduction in the field of climate policy.

Indeed, a significant majority $(85 \%+/-9 \%)$ of Swiss economic associations state they are in favour of incentive measures (i.e. taxes and permits). Figures 7 and 8 give more detailed results about this type of instruments and clearly show that Swiss economic stakeholders favour tradable certificates rather than taxes.

According to Figure 7, our survey shows that the favourite instruments to these economic associations are in this order: voluntary agreements are ranked first, information and education programmes second, international certificates third, national certificates fourth, taxes fifth, and command and control instruments were ranked the last.

According to the N-Persons Game Theory, this ranking was established based on the Condorcet Winner (CW) method (i.e. the alternate which beats all the others if on compares them even per pair), which is considered the best one so the result of a game (i.e. collective choice) reflects the structure of individual preferences.

This ranking clearly reflects the previous results regarding voluntary agreements (first position) and direct controls (last position). It also makes a difference between two types of incentive measures: taxes and tradable emissions permits or certificates. In fact, we can guess that taxes obtained a high score in Figure 6 because they were combined with permits under the "incentive measures" label. But taxes are probably perceived as a more stringent instrument compared to tradable certificates, both national and international as with the former measure the price is set by the government, whereas in the latter the price is set by the market. In addition, taxes imply a different structure of property rights, compared to freely distributed tradable certificates (cf. Baranzini et al. 2000). Indeed, with the former the polluter has to pay for each ton emitted, while with the latter, it receives an amount of emission rights free of charge. Of course, at the emitter's level, this implies that the tax is costlier than freely distributed tradable certificates. In addition, as pointed out by Vatter (2002), another reason for the weak success of taxes is that stronger redistributive measures (like an emission tax) create more identified winners and losers. In the political decision process, those who have to pay have often a strong lobby to combat such an amendment bill. The cost factors as well as every change of the status quo represent a threat to the introduction of ecological taxes (Vatter 2002).

Swiss economic associations were then asked what was their position on votes on four different kinds of energy taxes that were already submitted to the Swiss population (all the proposals were refused):

1. The "Solar initiative", which aimed to introduce a tax of Sfr. $0.05 / \mathrm{kWh}$ on non renewable energy,

2. The "Energy conservation package" to introduce a Sfr. $0.03 / \mathrm{kWh}$ incentive tax on energy to promote renewable forms of energy, 


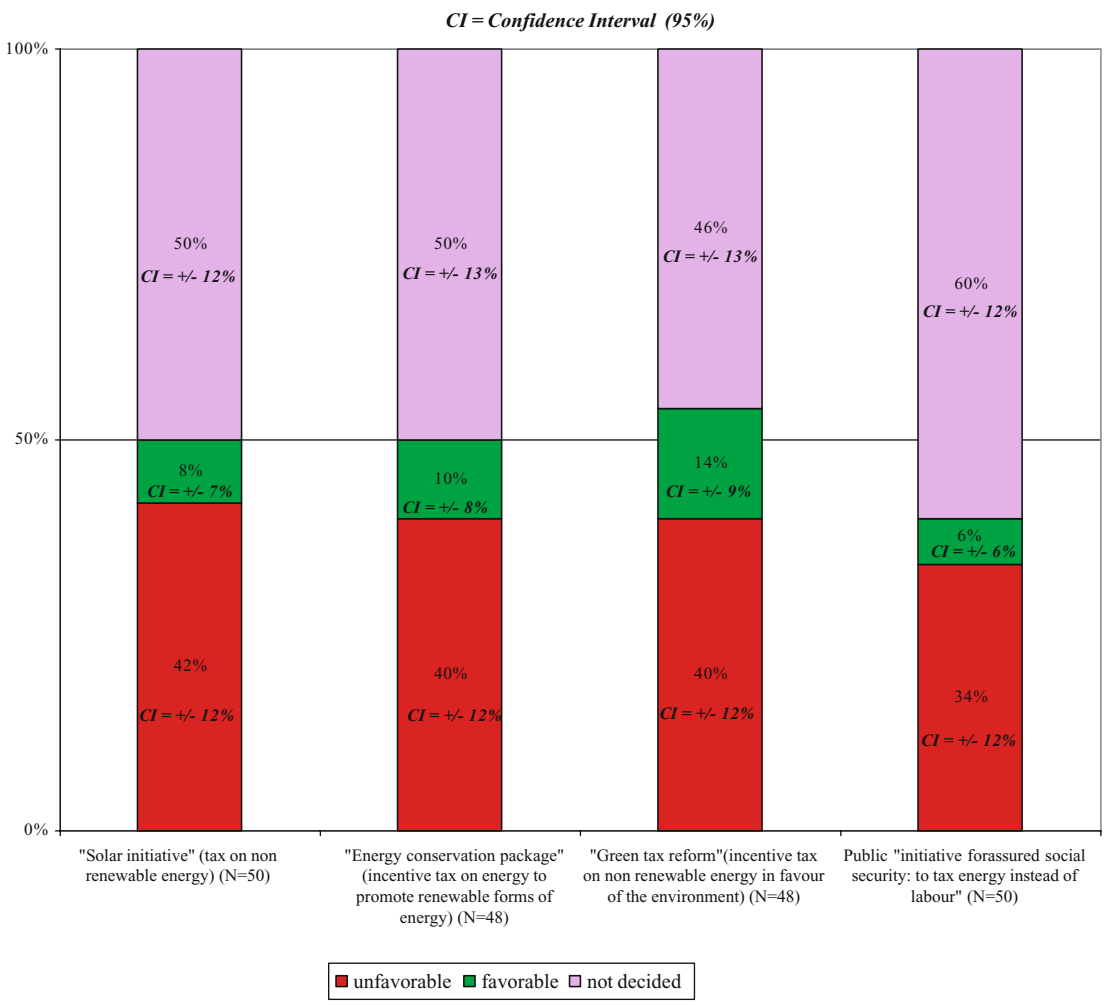

Fig. 8 Federal popular ballots on energy taxes: position of the Swiss economic associations

3. The "Green tax reform", an incentive tax on non-renewable energy of Sfr. 0.20 as a maximum; and finally

4. The "initiative for assured social security: to tax energy instead of labour".

The first three ballots took place on September 24, 2000 and the last one on December 2, 2001.

Figure 8 shows that half of the economic associations stated that they did not take position on these issues. However, one can wonder about the reasons for this: it may be possible that these associations did not want to show their opposition to the measure. The other half overwhelmingly took position against these green taxes and only a minority of the economic association were favourable to green taxes, which thus are less better accepted by economic associations that Figure 6 does let it show.

It appears that economic associations are more favourable to less stringent measures that leaves them a greater room for manoeuvre; the example of the efforts of some of them in favour of a "climate centime" instead of a tax on $\mathrm{CO}_{2}$ shows how reluctant they are to the implementation of a tax.

If we compare the results of both surveys - the 1997 one on 300 Swiss corporations and the 2003 one among 240 Swiss economic associations-we can raise a paradox in the behaviour of the Swiss economic associations concerning their acceptance of incentive measures, and 


\begin{tabular}{|c|c|c|c|c|c|c|}
\hline & $\begin{array}{c}\text { Voluntary } \\
\text { Agreements }\end{array}$ & $\begin{array}{c}\text { Information } \\
\text { Education }\end{array}$ & $\begin{array}{c}\text { Certificates } \\
\text { international }\end{array}$ & $\begin{array}{c}\text { Certificates } \\
\text { national }\end{array}$ & Taxes & $\begin{array}{c}\text { Command } \\
\text { and control }\end{array}$ \\
\hline $\begin{array}{c}\text { Economic } \\
\text { Associations }\end{array}$ & 1 & 2 & 3 & 4 & 5 & 6 \\
\hline $\begin{array}{c}\text { Environmental } \\
\text { Associations }\end{array}$ & 5 & 4 & 6 & 3 & 2 & 1 \\
\hline
\end{tabular}

Fig. 9 Ranking of preferences of forty-nine Swiss economic associations and four Swiss environmental associations for economic instruments. This ranking was established based on the Condorcet Winner $(\mathrm{Cw})$ method

in particular of an ecological tax, and more generally between measures accepted in theory and rejected in practice.

In order to go deeper into the analysis, we compared the answers from the economic associations with the ones obtained from four environmental associations. These results are not statistically representative due to the small number of answers from green associations and serve only to give a broad idea of their preferences, as all these four associations established the same classification.

The results summarized in Figure 9 show a clear opposition between economic lobbies and ecological interest groups. The former prefer voluntary agreements and market incentives. The latter are for command and control. These opposing views show the potential for paralysing the policy debate and express the mutual lack of trust of these pressure groups. The lack of consensus makes CBA difficult to apply, as the valuation of cost and benefits are discussed in a very controversial way when it comes to apply policy of climate change.

We suggest that a difference in the perception of economic instruments policy can be found in conceptual problems raised by an economic approach to climate change and not so much in technical difficulties related to CBA.

\subsection{Conceptual problems of economic approaches to the environment}

Neoclassical theory considers the natural environment as a free good, having no monetary value until its over exploitation makes it scarce and converts it into an economic good. The theory that tries to model this transformation considers the environment as an externality to the economic sphere. This surprises most researchers in the social sciences. Robert Hettlage expresses this astonishment as follows: "Externalities are built, whose exploration can be delegated to other sciences as they contaminate the model (this would at once clean the theory), if this explanation effort were necessary" (Hettlage 1993, p. 84).

The conceptual aspects arising in the economics environment relationship concern the notion of externality, the determination of non market values and the social learning process, which has to legitimate any policy in environment protection (cf. Söderbaum 2000).

\subsubsection{The environment: An externality?}

When it treats the environment as an externality, the concept of social cost is at the hearth of the debate. The externality argument states that market failures arise, when private benefits from some economic activity impose an uncompensated cost to someone else. Such a case directly pertains to pollution, but has a more general scope. Every time there is an immediate Springer 
benefit from an economic activity whose marginal cost is less than the expected marginal revenue because a third party bears part of the total costs, we are confronted with market failure. No incentive to reduce or to stop such an activity exists. The total cost to society is greater than the cost borne by the one who receives the private benefit. This situation calls for government intervention. The recommended policy is to ask the government to invoice the individual for the social cost created, for example through a $\mathrm{CO}_{2}$ tax. This method of justifying government intervention consistent with market rules raises a daunting question: to what degree can the private marginal cost be compared to the social one? Such a comparison would only be conceptually acceptable if the costs could be measured objectively (Buchanan 1969).

If pollution reduces this value and requires a tax to be introduced, it is followed by income transfers, which ultimately cannot be evaluated without value judgements.

\subsubsection{Non-market values}

The value of the natural environment as determined by a market refers to an economic use of it. Yet the value of the environment is also determined outside the market and independently of any economic use. Because the natural environment has an intrinsic value, the market cannot exclusively determine its worth. Likewise, failure to subject the natural environment to economic use-albeit possible on both a technological and a normative plane-can give the environment a "non-use" value that economists readily associate with an opportunity cost. This cost is part of every economic choice, and is defined by the fact that any economic decision related to managing scarce productive resources necessarily implies giving something up (cf. Fankhauser 1995).

Climate change policy essentially finds its legitimacy in the change of non-market values determined by its social perception. This change takes place over a long time, and is codified in laws, regulations, morals and customs, which reflect the fact that people are increasingly aware of problems related to the protection of the environment, despite the fact that the intensity of this awareness can vary. Social concern about an undamaged environment can be supplanted by other, temporarily more worrying problems such as unemployment.

It is therefore illusory to think that changing social perceptions of the natural environment will only change the institutions of a society and leave its perceptions of the economy untouched. Accordingly, we cannot observe constant and inalterable economic behaviour, but rather a permanent interaction between social values and human behaviour. The origin of changing motivations in individual as well as collective behaviour thus becomes crucial to the building of an operational climate change policy.

However, there is no scientific criterion that enables us to move from an individual to a collective level. Society's economic welfare cannot be defined by simply adding up individual behaviours, and then treated as a simple problem of factor allocation. A change in the social utility function does not take into account of the factors, which induced it (Feldman 1983).

\subsubsection{Environment protection: A social learning process}

In practice, cost-benefit analysis assumes away those factors and relies on engineering expertise. Even if, due to the complexity of the criteria used, impact assessments are made by teams, which also include social scientists, most analyses use a multi-criteria approach, where the weighting of the different explanatory factors becomes essential. Engineers apparently prefer the weighted sum approach, which does not differentiate between explanatory factors on a qualitative level. Thus, if one variable is considered less important, the low weighting 
assigned to it cannot do justice to cases where this variable - for example above a certain emission level and sometimes only in relation to another variable - can, during the valuation procedure, take on a totally different meaning.

A learning aspect not only makes it likely that the value function of the criteria will be changed, but also increases the information of the actors concerned by the project and their knowledge of possible interactions between different variables. Consequently, we encounter a problem that has become familiar by now, namely the estimation of the social values and costs submitted to normative judgements, which varies according to the changing social perception of climate change over time. In other words, taking the related costs into account is a normative process, dependent on a politico-legal context, which is also supposed to reflect these changes. This conclusion thus rules out any allegedly objective valuation method.

Recent developments try to weight the different criteria by a normalize approach involving non-scientists in the assessment effort (for a survey of the issues and methods used in this field, see Rotmans and van Asselt 2002). Therefore, the actors' information improve during the negotiation. The normative dimension of policy recommendations becomes part of the analysis. As our survey has shown, economic actors such as special interest groups stress that any assessment must be combined with a negotiation process. They expect increased transparency in applying valuation criteria, as well as a learning effect for all the partners concerned by a policy recommendation, in order to improve the instruments that are to be introduced with a view to enhancing climate change.

\section{Conclusion: Towards a socially accepted policy mix}

The debate about values, the internalisation of social costs and the explicit recognition of ethical aspects make a single minded, exclusive economic approach to climate change policy obsolete. Such an approach contributes to the problems of the social acceptance of economic instruments. In order to overcome this obstacle the following two interrelated research strategies are followed:

- The first research strategy consists of conventional models, that take the environment into account, either through public goods theory or through property rights theory. These two theories cover the main issues in environmental economics.

- The second strategy refers to more global models, which try to feature relationships between economics and the biosphere. In the same way, models, which add a social dimension in order to come closer to the concept of sustainable development (where these three levels: economic, environmental, social are included) also belong to this group, and cover the field of ecological economics.

Finally, the crucial point is the integration of the ethical dimension in the traditional theoretical representations of the economy that society has adopted (Bürgenmeier 1993). The trend is to delegate ethical questions to the human sciences and thereby to "clean" the economic model, which then constitutes the main reference. Ethics, as well as the environment, are then being treated as an externality to the market. This distinction makes it possible to work on a "scientific" level and root criteria in a positive sense. Theology and moral philosophy are assigned the task of maintaining the social representation of the workings of the economy as intact as possible, treating these aspects outside the economic sphere. The intellectual challenge lies not only in preventing such a development (which is already well under way if one is to judge by the many institutes specialised in economical ethics), but also in integrating ethical considerations in economic reasoning itself (Harsani 1955). The Springer 
promotion of economic policies of climate change has to be completed by social policies in order to catch such ethical aspects (Spash 2002). Such social policies not only include transfers of income, but also basic values of the institutional setting of the market, such as legal regulation of "fairness" and non-discriminatory practices. This extension inevitably exposes economics to a dilemma.

- Economic reasoning tries to reduce pollution at the lowest possible cost. It proposes an optimisation calculus that equalises the marginal cost with the marginal benefit of any economic activity. If many actors on a market are responsible for a given polluting emission, it recommends a policy reducing these where the marginal costs of doing so are smallest. Following the efficiency criterion, economic reasoning therefore allows for a differentiated treatment of actors on a market according to their cost or utility functions.

- On the contrary, moral reasoning, often legally codified, is concerned with equality of treatment, which originates in a normative judgement (for example, through the collective memory of a community). This normative judgement may also come out of a political process. If this process is democratic, it is supposed to express the opinion of a majority. Once economic theory recognises that there may be as many normative judgements as actors on the markets (and as many individual actions), legal reasoning only refers to collective preferences. Therefore, implementation of climate change policies is normative by nature. Economic modelling has to be extended to the understanding of a political process.

\section{References}

AEN-NEA (Nuclear Energy Agency) (2005) Projected costs of generating electricity - 2005 update. OECDNuclear Energy Agency, OECD/IEA. Paris, France

Anaheim HA (2002), Impacts of climate change in monetary terms? Issues for Developing Countries. In Baranzini A, Buergenmeier B (Guest Editors) Climate change: issues and opportunities for developing countries. Special Issue of the Int J Global Env Issues, November 2002, 2(3/4):223-239

Arrow KJ (1951) Social choice and individual values. Wiley, New York

Arrow KJ, Lind RC (1970) Uncertainty and the evaluation of public investment decisions. Am Econ Rev 60(3):364-378

Arrow KJ, Parikh, J, Pillet G (1996) Decision-Making Frameworks for addressing climate change, in IPCC, cit. below, pp 52-77

Bahn O, Drouet L, Edwards N, Haurie A, Kypreos S, Stocker T, Vial J-P (2006a) Optimal economic growth under climate change threats. Climatic Change, DOI 10.1007/s10584-006-9108-4, this issue

Bahn O, Edwards N, Knutti R, Stocker TF (2006b) Climate policy preventing an Atlantic thermohaline collapse. Climatic Change (submitted)

Baranzini A, Goldemberg J, Speck S (2000) A future for carbon taxes. Ecol Econ 32(3):395-412

Baranzini A, Chesney M, Morisset J (2003) The impact of possible climate catastrophes on global warming policy. Energy Policy 31(8):691-701

Barde JP (1997) Economic instruments for environmental protection: experience in OECD countries. in applying market-based instruments to environmental policies in China and OECD countries, Paris, OECD, pp 31-58

Buchanan J (1969) Cost and choice, an inquiry in economic theory. Chicago University Press, Chicago

Bürgenmeier B (1993) Ethical aspects of environmental protection. In: Vernet JP (ed), Environmental contamination, studies in environmental sciences, no. 55. Amsterdam, Londres, New York, Tokyo: Elsevier

Bürgenmeier B, Harayama Y, Wallart N (1997), Théorie et pratique des taxes environmentales, Economica, Paris

Bürgenmeier B (2003) Modelling equity: a debate about values, in Environment Modelling and Assessment, No 8 , pp. $165-174$

Bürgenmeier B, Ferrier C, Germond-Duret C, Ingold K, Perret S (2006) Acceptation des instruments de marché dans la politique climatique suisse: enquête auprès des principaux acteurs économiques suisses, forthcoming (see also Perret S (2004) "L'acceptabilité des instruments économiques dans le domaine de la politique climatique en Suisse: résultats préliminaires", Working Paper, No WP4-25 
Cropper M (2000) Has economic research answered the needs of environmental policy?. J Environ Econ Manag 39:328-350

Falk I, Mendelsohn R (1993) The economics of controlling stock pollutants: an efficient strategy for greenhouse gases. J Environ Econ Manag 25:76-88

Fankhauser S (1995) Valuing climate change. the economics of the greenhouse. Earthscan, London

Funtowicz SO, Ravetz JR (1994) The worth of a songbird: ecological economics as a post-normal science. Ecol Econ 10:197-207

Henry C (1974) Investment decisions under uncertainty: the irreversibility effect. Am Econ Rev 64(6):10061012

Hettlage R (1993) Ökonomie auf dem Weg zur Sozialwissenschaft? Revue Suisse de Sociologie 19(1)

Intergovernmental Panel on Climate Change (IPCC) (1996) climate change 1995. economic and social dimensions of climate change. contribution of working group iii to the 2nd assessment report of the IPCC. WMO and UNEP, New York, Cambridge (U.K.): Cambridge University Press

Intergovernmental Panel on Climate Change (IPCC) (2000) special report on emission scenarios, a special report of the working group iii. of intergovernmental panel on climate change, Cambridge University Press, Cambridge (U.K.)

Intergovernmental Panel on Climate Change (IPCC) (2001) climate change 2001: mitigation. contribution of working group iii to the third assessment report of the intergovernmental panel on climate change, Cambridge University Press

Knutti R, Stocker TF, Joos F, Plattner G-K (2002) Constraints on radiative forcing and future climate change from observations and climate model ensembles. Nature 416:719-723

Loulou R, Goldstein G, Noble K (2004). Documentation for the MARKAL family of models. Energy Technology Systems Analysis Programme (ETSAP), October 2004

Maddison D (1995) A cost-benefit analysis of slowing climate change. Energy Policy 23(4/5):337-346

Manne AS, Richels RG (2005) Global climate decisions under uncertainty. a paper presented at annual meeting of the international energy workshop 2005, 5-7 July 2005 at the Pa-lu-lu Plaza Kyoto, Kyoto, Japan

Mishan EJ (1980) How valid are economic evaluations of allocative changes? J Econ Issues XIV(1):143-161

National Research Council (2002), Abrupt climate change: inevitable surprises. The National Academics Press, Washington, DC

Nordhaus, WD (1993) Rolling the DICE: an optimal transition path for controlling greenhouse gases. Resou Energy Econ 15:27-50

Olson M (1971) Logic of collective action: public goods and the theory of groups. Harvard Universty Press, revised edition, Cambridge (Mass.)

Rafaj P (2005): Analysis of policies contributing to sustainability of the global energy system using the global multi-regional MARKAL model (GMM), Ph.D. Thesis, Nr. 16122, ETH Zürich 2005

Rafaj P, Kypreos S, Barreto L (2005) Flexible carbon mitigation policies: Analysis with a global multiregional MARKAL model. In: Haurie A, Viguier L (eds), Coupling climate and economic dynamics. Kluwer Academic Publishers, Dordrecht, The Netherlands, pp 237-66

Rotmans J, van Asselt MBA (2002) Integrated assessment: current practices and challenges for the future. in Abaza H, Baranzini A (eds) implementing sustainable development. integrated assessment and participatory decision-making processes. Edward Elgar, Cheltenham, UK, pp 78-116

Söderbaum P (2000) Ecological economics. Earthcan, London

Spash CL, Carter C (2001) Environmental valuation in Europe: findings from the concerted action, policy research brief, No 11, European Commission DG-XII, Cambridge Research for Environment (CRE)

Spash CL (2002) Greenhouse economics, value and ethics, Routledge, London

Thalmann, Ph (2001) The public acceptance of green taxes: two million voters express their opinion. NCCR - WP4 Working Paper 1

United Nations Framework Convention on Climate Change (UNFCCC): 1999, The Kyoto protocol to the convention on climate change, UNFCCC Climate Change Secretariat and UNEP, UNEP/IUC/99/10, Geneva, Switzerland

Vatter A (2002), Erfolgsfaktoren klimapolitischer Abstimmungsvorlagen, Büro Vatter

Viguier L, Barreto L, Haurie A, Kypreos S, Rafaj P (2006) Modelling endogenous learning and imperfect competition effects in climate change economics. Climatic Change, DOI 10.1007/s10584-006-9070-1, this issue

Wallart N (2000), The political economy of environmental taxes. Edgar Elgar, Cheltenham 